\title{
Spinal hematoma following subarachnoid block in a patient with postpartum cardiomyopathy
}

\author{
R Mandhyan ${ }^{1}, \boldsymbol{R}$ Wadhwa $^{2}$, SP Singh $^{3}$, Phatri $^{4}$ \\ Specialist ${ }^{1}$, *Assistant Professor ${ }^{2}$, Department of Anaesthesiology and Critical Care, GTB Hospital, \\ Shahdara, Delhi. Senior Consultant ${ }^{3}$, Dept of Anaesthesiology and Critical Care, BL Kapoor \\ Hospital, New Delhi. Consultant Neurosurgeon ${ }^{4}$, Maharaja Agrasen Hospital, New Delhi, India.
}

\section{Corresponding author: drrachnawadhwa@gmail.com}

Spinal anaesthesia is considered the best and safest way of providing anaesthesia for infra-umbilical surgeries. It is a blessing for patients with high risk for general anaesthesia, but at times it may be associated with fatal complications. Spinal haematoma is one such rare complication of subarachnoid block. Peripartum cardiomyopathy is also an added concern in obstetric patients.

Keywords: subarachnoid block, spinal haematoma, paraplegia, peripartum cardiomyopathy

\section{Introduction}

Intraspinal haemorrhage is one of the rare complications following subarachnoid block (SAB). In a large series reviewed by Sage, including over 100,000 procedures, no such occurrence was observed ${ }^{1}$. The case presented here is a postoperative complication of SAB in an obstetric patient in the form of spinal haematoma along with co-incidental peripartum cardiomyopathy. The haematoma was drained surgically; patient recovered from cardiomyopathy gradually over a period of time.

\section{Case Report}

A 25 years old female patient was admitted to the medicine department with complaints of motor weakness along with sensory loss in both lower limbs, following caesarian section done under a SAB 24hrs back. Patient gave no history of fever, trauma, seizures, backache, coagulopathy or anticoagulant medication, paraesthesia or motor weakness in past before surgery. SAB was given at a private hospital in L3-L4 space using bupivacaine $12 \mathrm{mg}$ and a $25 \mathrm{G}$ Quincke needle in a single prick. She was sedated post-delivery of baby and even 24hours after SAB she could not move her lower limbs.MRI spine showed haemorrhagic collection in epidural space at the level of L1-L2 and below causing compression of cauda equina. She also had chest pain and dyspnoea. Her ECG showed poor $R$ wave progression and $2 D$ echocardiography revealed an ejection fraction of $25 \%$ diagnosing peripartum cardiomyopathy. Nervous system examination revealed motor power $5 / 5$ in both upper limbs and $0 / 5$ in both lower limbs, sensory level at T12- L1 with bladder and bowel involvement. Other systems were normal. Her preoperative blood investigations were within normal limits. She was given a general anaesthetic and a large epidural hematoma extending from L1 to L4 along with granulation tissue was found which was sent for histopathology. Cord decompression was completed in about 2 hours and after reversing anaesthesia she was sent to cardiac care unit for monitoring.

Postoperatively, patient did not regain any motor power in lower limbs. Subsequent 2D echo showed ejection fraction of $46 \%$. Patient was discharged home after one week. Histopathology revealed non-specific granulation tissue suggesting idiopathic aetiology. In the follow up motor power of $3 / 5$ was regained after 12 months of regular physiotherapy.

\section{Discussion}

Intraspinal hematoma is a known complication after subarachnoid block (SAB). Spinal haematoma can be idiopathic or have multiple aetiologies like bleeding diathesis, anticoagulant medications, spinal tumors and vascular malformations. The site may be extradural, subdural or subarachnoid compartments; of which epidural space is the commonest. Spinal hematoma may cause cauda equina syndrome and paraplegia. Kreppel D. et al reviewed 613 cases of spinal haematoma; $29.7 \%$ cases had no aetiological factor identified as the cause of bleeding $^{2}$. The cause of the haematoma in this patient was also considered idiopathic as there 
was no evidence of coagulopathy or tumour. She could not regain motor power in her limbs even 24 hours after the SAB. Normally, duration of sensory blockade (time to return of complete sensation in the operative site or regression of two dermatomes) following a $12 \mathrm{mg}$ dose averages 2 hours. The time to return of complete motor ability with $12 \mathrm{mg}$ Bupivacaine averages $3 \frac{1}{2}$ hours.

Cases related to anticoagulant therapy and vascular malformations represent the second and third most common categories. Domenicucci et al reviewed 106 cases of non traumatic acute spinal subdural hematoma; $40.5 \%$ of the cases were associated with coagulopathies and $44.9 \%$ with lumbar puncture ${ }^{3}$. Spinal tumors like ependymomas are also an important cause of spinal haematoma. Patients are asymptomatic pre-operatively and $\mathrm{SAB}$ may precipitate neurological deterioration; the mechanism being "spinal coning" because of pressure difference above and below the block due to cerebrospinal fluid leak ${ }^{4}$. It is hypothesized that "locus minoris resistentiae" along with increased pressure in the interior vertebral venous plexus may contribute to spinal haemorrhage ${ }^{2}$. Most hematomas are localized dorsally to the spinal cord at the puncture level as seen in our case. Clinically the patient experiences a typical severe lumbar pain progressing to complete flaccid paralysis.

Investigation of choice is MRI being highly sensitivity in delineating cranio-caudal extension and ventro-dorsal location. Treatment is surgical decompression as early as possible. Less severe the preoperative neurological deficit and quicker the surgical decompression, the chances of complete recovery are better ${ }^{6}$. It is therefore essential to recognize the relatively typical clinical presentation of spinal haematoma to allow correct diagnosis and therapeutic measures to be taken to maximize patient outcome. Our patient also developed postpartum cardiomyopathy which is a rare but serious complication of pregnancy; incidence being 1: 1300 to 1: 4000 live births ${ }^{7}$. Multiparity is a risk factor for the development of postpartum cardiomyopathy, suggesting that previous exposure to foetal or paternal antigen may elicit an abnormal myocardial inflammatory response . $^{8}$

The report draws attention to the need of early detection of cord compression and surgical decompression to provide the best outcome.

\section{References}

1. Sage DJ. Epidurals, Spinals and bleeding disorders in pregnancy: a review. Anaesthesia Intensive Care 1990;18: 319-26.

PMid:2221324

2. Kreppel D, Antoniadis G, Seeling W. Spinal haematoma: a literature survey with meta analysis of 613 patients. Neurosurgery review. 2003;26(1):1-49. PMid:12520314 http://dx.doi.org/10.1007/s10143-002-0224-y.

3. Domenicucci M, Ramieri A, Ciapetta P, Delfini R. Non traumatic acute spinal subdural haematoma: report of five cases and review of the literature. Journal of Neurosurgery1999;

91:65-73. PMid:10419371

4. Jaeger M, Rickels E, Schmidt A, Samii M, Blomer U. Lumbar ependymoma presenting with paraplegia following attempted spinal anaesthesia. British Journal of Anaesthesia 2002; 88 (3):438-40. PMid: 11990280 http://dx.doi.org/10.1093/bja/88.3.438 5. Singh D, Chauhan M, Gupta V, Chopra S, Bagani MR. Spinal subdural haematoma: A rare complication of spinal anaesthesia: A case report. Turkish Neurosurgery 2008; 18:3,3246. PMid: 18814128 6. Lawton MT, Porter RW, Heiserman JE, et al. Surgical management of spinal epidural hematoma: relationship between surgical timing and neurological outcome. Journal of Neurosurgery 1995; 83: 1-7. http://dx.doi.org/10.3171/jns.1995.83.1.00 01. PMid:7782824

7. Mielniczuk LM, Williams K, Davis DR, et al. "Frequency of peripartum cardiomyopathy". American journal of Cardiology. 2006; 97 (12): 1765-8. http://dx.doi.org/10.1016/j.amjcard.2006.01.03 9. PMid:16765131

8. Sliwa K, Fett J, Elkayam U. "Peripartum cardiomyopathy". Lancet 2006; 368 (9536): 687-93.http://dx.doi.org/10.1016/S0140$\underline{6736(06) 69253-2}$ 